\title{
Effect of a program to control perioperative blood glucose on the incidence of nosocomial infections in patients with diabetes: A pilot study ${ }^{*}$
}

\author{
Javier Ena ${ }^{1 \#}$, Rosa Casañ ${ }^{2}$, Maria José Carratalá ${ }^{1}$, Edith Leutscher ${ }^{3}$ \\ ${ }^{1}$ Department of Internal Medicine, Hospital Marina Baixa, Alicante, Spain; \\ \#Corresponding Author: ena jav@gva.es, mjosecarratalá@eresmas.com \\ ${ }^{2}$ Division of Endocrinology and Metabolism, Hospital Marina Baixa, Alicante, Spain; rosacasany@yahoo.es \\ ${ }^{3}$ Division of Preventive Medicine, Hospital Marina Baixa, Alicante, Spain; leutscher edi@gva.es
}

Received 20 February 2012; revised 28 March 2012; accepted 29 April 2012

\begin{abstract}
Aim: To evaluate the safety and effectiveness of a pilot program to control perioperative blood glucose in patients with diabetes. Methods: A pre-post intervention study was conducted in a 280-bed hospital in Spain. In the year 2008 we implemented perioperative insulin protocols aimed at blood glucose values from 80 to 180 $\mathrm{mg} / \mathrm{dL}$. Surgical patients with diabetes admitted on year 2009 (intervention group) were compared with a control group of patients with diabetes admitted for surgery on year 2007, matched 1:1 by traditional wound class. Results: We analyzed 96 patients. Implemented protocols were followed in $48 \%$ of patients intra-operatively and $75 \%$ of patients postoperatively. Patients in the intervention group had reductions in blood glucose at surgery $150+/-61 \mathrm{mg} / \mathrm{dL}$ vs. $172+/-53 \mathrm{mg} / \mathrm{dL} ; \boldsymbol{p}=\mathbf{0 . 0 5}$ ), greater proportion of target glucose values throughout hospitalization $(67 \%$ vs. $55 \% ; p=0.07)$, and reductions in the incidence of nosocomial infections after controlling for confounders (Odds Ratio: $0.20 ; 95 \%$ Confidence Intervals: $0.06-0.72 ; p=0.014$ ) when they were compared with the control group: The incidence of hypoglycemia was similar between two groups $(0.12 \%$ vs. $0.10 \%, p=0.867)$, respectively. Conclusion: Although our protocol needs improvements to increase implementation it was useful to control blood glucose safely and for reducing nosocomial infections.
\end{abstract}

Keywords: Diabetes; Insulin/Administration and Dosage/Therapeutic Use; Surgical Site Infection;

*Conflict of interest: The authors declare that they have not conflict of interest.
Nosocomial Infection

\section{INTRODUCTION}

The association between diabetes mellitus and greater risk of suffering from surgical site infections has been recognized for many years [1-3]. Hyperglycemia impairs granulocyte functions including adherence, chemotaxis, phagocytois, and bactericidal activity [4]. Improving glycemic control in the preoperative period can reduce wound complications and nosocomial infections in patients with coronary artery by-pass graft $[5,6]$. The Centers for Disease Control and Prevention (CDC) Hospital Infection Control Practices Advisory Committee recommends that preoperative blood glucose should be held to less than $200 \mathrm{mg} / \mathrm{dL}$ [7]. The recently published standards for diabetes care in hospitalized patients admitted to general medicine or surgical wards recommended maintaining blood glucose values below $180 \mathrm{mg} / \mathrm{dL}$ if they can be achieved safely [8]. Most experience of controlling diabetes in the operative period has been reported for patients undergoing cardiac surgery. There is insufficient evidence that strict blood glucose control prevents surgical site infections in patients undergoing abdominal or orthopedic surgery; moreover, the relative risk of infection compared to the risk of hypoglycemia has not been established.

In the present study we evaluated the impact of a glycemic control protocol aimed at achieving blood glucose levels between $80-180 \mathrm{mg} / \mathrm{dL}$ on the perioperative period in patients undergoing abdominal and orthopedic surgery. Specifically we evaluated the proportion of patients with an appropriate glucose control, the risk of hypoglycemia, the incidence of surgical site infections and other nosocomial infections, all-cause related mortality and the hospital length of stay after implementing a specific protocol for controlling blood glucose intra- and 
postoperatively.

\section{METHODS}

\subsection{Setting}

Hospital Marina Baixa is a 280-bed center belonging to the National Health System providing care for 210,000 inhabitants in the East coast of Spain. The General Surgery Department and the Orthopedics Department have assigned a total of 68 beds.

\subsection{Type of Study}

We carried out a quasi-experimental before and after study. Strict blood glucose control was aimed at fasting values between 80 and $180 \mathrm{mg} / \mathrm{dL}$. To assess the impact of strict glucose control on morbidity and mortality we compared outcome variables before and after implementing a protocol for intra- and postoperative blood glucose control. A prospective group of patients with strict blood glucose control was compared with an historical control group matched by wound contamination class. The study was approved by the institutional review board of the Hospital Marina Baixa.

\subsection{Intervention}

The proposed perioperative glucose control protocol was presented and discussed with anesthetists, general surgeons, orthopedic surgeons, and nurses. The protocol included the following steps: 1) Stopping oral hypoglycemic agents in all patients on admission; 2) Starting a intra- and postoperative insulin regimen with two algorithms depending on patients' preoperative blood glucose control and type of diabetes treatment (Addendum); 3) Starting a postoperative basal-bolus-correction insulin regimen [9]; 4) Assessment of diabetes treatment at discharge according to hemoglobin ${ }_{\mathrm{A} 1 \mathrm{c}}$ values on admission. Under usual care patients hospitalized with diabetes had capillary glucose readings every 6-hour if fasting or before breakfast, lunch and dinner if they are not fasting. Every patient had a capillary blood glucose reading at 06:00 h. on the day of surgical intervention.

Patients on oral hypoglycemic agents with preadmission appropriate blood glucose control, had discontinuation of oral drugs, and before the induction of anesthesia they received an infusion consisting of $2500 \mathrm{~mL}$ of $5 \%$ dextrose in water with $60 \mathrm{mEq}$ of potassium chloride, and corrections with subcutaneous injections of regular human insulin every 4 hour guided by capillary blood glucose.

Patients on treatment with insulin or showing poor preadmission blood glucose control (glucose $>200$ $\mathrm{mg} / \mathrm{dL}$ or $\mathrm{Hb}_{\mathrm{Alc}}>8 \%$ ) received before the induction of anesthesia an infusion consisting of 1500 of $10 \%$ dex- trose in water with $60 \mathrm{mEq}$ of $\mathrm{ClK}$ and continuous intravenous insulin (50 units of regular human insulin in 500 $\mathrm{mL}$ of $0.9 \%$ saline solution) at an infusion rate according to hourly capillary blood glucose and individual requirements (Addendum). Pre- and intra-operative treatment was typically started at $06.00 \mathrm{~h}$. AM on the day of surgery, and maintained throughout patients' fasting state. Thereafter, subcutaneous insulin was administered according a basal-bolus correction regimen. Insulin glargine was used as basal insulin, and insulin aspart was used as bolus and correction dosages according to our institution protocol [9]. Adherence to glucose control protocols was assessed by reviewing clinical records.

\subsection{Patients}

In the present study we included adult patients with type 2 diabetes undergoing elective abdominal or orthopedic surgery (hip replacement), with no active infection up to the date of surgery, and hospitalized for at least 3 days. We collected the following information from the clinical record: age, sex, type of diabetes therapy, recent haemoglobin $_{\mathrm{Alc}}$, comorbidities (Charlson scale) [10], Acute Physiologic and Chronic Health Evaluation (APACHE-II) score [11], American Society of Anesthesiologists physical status classification (ASA score) [12], most recent blood glucose before surgery, duration of surgical intervention, wound class (clean, clean-contaminated or contaminated surgery classification) [13], National Nosocomial Infections Surveillance System (NNIS) classification [14], and presence of laparoscopic or open surgery. As outcome variables we collected: adherence to pre- and postoperative glycemic control protocols, capillary glucose readings during hospitalization, presence of hospital acquired infection diagnosed according to Centers for Disease Control and Prevention (CDC) criteria $[15,16]$, rate of severe hypoglycemia (blood glucose $<60 \mathrm{mg} / \mathrm{dL}$ ), hospitalization length, and all cause mortality at 30-day. Surveillance was extended to 30 days after hospital discharge to detect hospital infections clinically developed at home. Post-discharge surveillance was achieved by reviewing all of the emergency department forms and by telephone.

\subsection{Statistical Analysis}

Data is presented in absolute numbers and proportions for nominal variables. Mean \pm standard deviation (SD) is use for continuous variables. Outcomes were analyzed with the use of a Student's $t$-test and the Pearson chisquare or Fisher exact test for proportions. To assess the independent contribution of the glycemic control program on the incidence of nosocomial infections we carried out a logistic regression analysis using as control variables NNIS classification, use of laparoscopic sur- 
gery and length of hospitalization. $P$ values less than 0.05 were considered statistically significant. Data analysis was performed using SPSS/PC v. 15 as statistical package (SPSS inc. Chicago, IL, USA)

\section{RESULTS}

From January through December 2009 (post-intervention group), 1051 patients were admitted to the Department of Surgery of whom 161 (15\%) had type 2 diabetes as secondary diagnosis. In the same period, 997 patients were admitted to the Department of Orthopedics and Traumatology of whom $61(6 \%)$ had type 2 diabetes as secondary diagnosis. A total of 61 consecutive discharge clinical records were analyzed for inclusion in the study, being 13 excluded due to lack of surgical intervention ( $n$ $=3$ ), presence of active infection on admission $(n=4)$, and urgent surgery $(n=4)$. From our institutional database registry we selected for inclusion from January through December 2007 (control group) an eligible patient with type 2 diabetes matched by wound class with those included in the post-intervention group.

\subsection{Patient Characteristics}

We analyzed 48 patients from the post-intervention group, and 48 patients from the control group (Table 1). The clinical and demographic characteristics were similar

Table 1. Characteristics of patients entering the study.

\begin{tabular}{|c|c|c|c|}
\hline & Post-Intervention Group $(N=48)$ & Control Group $(N=48)$ & $P$ \\
\hline Age, years (mean $+/-$ SD) & $70.69 \pm 10.73$ & $69.10 \pm 10.39$ & 0.465 \\
\hline Gender, male (\%) & $28(58)$ & $25(52)$ & 0.682 \\
\hline Diabetes duration, years (mean $+/-\mathrm{SD})$ & $15.46 \pm 10.65$ & $9.80 \pm 6.15$ & 0.108 \\
\hline Hemoglobin $_{\mathrm{Alc}}(\%)$ & $7.21 \pm 2.10$ & $7.06 \pm 1.56$ & 0.791 \\
\hline Diabetes treatment $(\%)$ & & & 0.192 \\
\hline Diet & $4(8)$ & $1(2)$ & \\
\hline Oral hypoglycemic agents & $25(53)$ & $34(71)$ & \\
\hline Insulin & $16(32)$ & $12(25)$ & \\
\hline Oral hypoglycemic agents + insulin & $3(7)$ & $1(2)$ & \\
\hline Charlson score $($ mean $+/-$ SD) & $2.46 \pm 1.47$ & $2.23 \pm 1.65$ & 0.475 \\
\hline APACHE II score (points) & $7.46 \pm 1.92$ & $8.40 \pm 3.08$ & 0.077 \\
\hline ASA classification (\%) & & & 0.189 \\
\hline I & $1(2)$ & $0(0)$ & \\
\hline II & $17(44)$ & $15(33)$ & \\
\hline III & $17(44)$ & $28(63)$ & \\
\hline IV & $4(10)$ & $1(2)$ & \\
\hline V & $0(0)$ & $1(2)$ & \\
\hline Wound class $(\%)$ & & & 1.000 \\
\hline Clean & $9(19)$ & $9(19)$ & \\
\hline Clean-contaminated & $25(52)$ & $25(52)$ & \\
\hline Contaminated & $14(29)$ & $14(29)$ & \\
\hline NNSI index (\%) & & & 0.161 \\
\hline 0 & $5(10)$ & $6(12)$ & \\
\hline 1 & $13(27)$ & $21(44)$ & \\
\hline 2 & $21(44)$ & $11(23)$ & \\
\hline 3 & $9(19)$ & $10(21)$ & \\
\hline Laparoscopic surgery (\%) & $24(50)$ & $19(40)$ & 0.305 \\
\hline Length of surgical intervention (min) & $185.25 \pm 77.96$ & $135.96 \pm 64.59$ & 0.001 \\
\hline
\end{tabular}

Data are no [\%] or mean values [standards deviation]; ASA American Society for Anesthesiology; NNSI National Nosocomial Infection Surveillance (NNIS) classification: The NNIS basic surgical site risk index is composed of the following criteria: American Society of Anesthesiologists score of 3, 4, or 5 (1 point); wound contamination degree contaminatd or dirty ( 1 point); and duration of surgery greater than 120 min (1 point). 
between two groups except for APACHE II score (7.46 vs. $8.40, p=0.07$ ) and duration of surgical intervention $(185.25 \pm 77.96 \mathrm{~min}$ vs. $135.96 \pm 64.59 \mathrm{~min} ; p=0.001)$ between post-intervention and control group, respectively.

\subsection{Process-of-Care and Outcome Measures}

Our pre-operative and operative glycemic control was followed in the post-intervention group in $48 \%$ patients, and in the control group in $2 \%$ of patients $(p=0.000)$. Use of basal-bolus-correction insulin dosage was observed in $75 \%$ of patients in the post-intervention group compared with $40 \%$ of patients in the control group ( $p=$ 0.008). Hemoglobin ${ }_{\mathrm{Alc}}$ blood test orders did not change significantly between two periods (50\% vs. $48 \%$; $p=$ 0.412) (Table 2).

Regarding laboratory indicators, there was an almost significant reduction in the mean glucose values prior to surgery in the post-intervention group compared to the control group (150.50+/- 61.60 vs. $172.54+/-53.55$; $p$ $=0.05)$. The proportion of glucose values prior surgery that were within the target range in the two groups were $73 \%$ vs. $52 \% ; p=0.038$. However, after surgery the use of insulin in basal-bolus correction regimen increased the proportion of target glucose values in the post-interven- tion group compared with the control group, respectively ( $65 \%$ vs. $59 \% ; p=0.000)$. The rates of severe hypoglycemia were similar between two groups $(0.12 \%$ vs. $0.10 \% ; p=0.894)$, respectively.

The post-intervention group had borderline significant reductions in the incidence of surgical site infections $(17 \%$ vs. $33 \%, p=0.06)$, and not so in other nosocomial acquired infections ( $15 \%$ vs. $21 \%, p=0.594)$ compared with the control group. However, there were significant differences between two groups in logistic regression analysis after controlling for confounders such as: NNIS classification, use of laparoscopic surgery and length of hospitalization (Table 3).

We did not find differences in other outcomes analyzed within three months such as deaths (4\% vs. 13\%, $p$ $=0.268)$ and hospital readmissions ( $0 \%$ vs. $6 \%, p=$ 0.242 ) between post-intervention and control groups, respectively.

\section{DISCUSSION}

This pilot study shows that our perioperative protocol for blood glucose control is safe and reduces patient morbidity. The independent contribution of the protocol was 50 percent reduction in the rate of surgical site infections. Additionally, we observed a reduction in other nosocomial infections. Most importantly adverse events

Table 2. Process-of-care and outcomes evaluated.

\begin{tabular}{|c|c|c|c|}
\hline & Post-intervention Group $(N=48)$ & Control Group $(N=48)$ & $P$ \\
\hline Recent haemoglobin ${ }_{\mathrm{Alc}}$ available (\%) & $24(50)$ & $20(42)$ & 0.422 \\
\hline Glucose $(\mathrm{mg} / \mathrm{dL})$ at surgery & $150.50 \pm 61.60$ & $172.54 \pm 53.55$ & 0.396 \\
\hline Glucose $(\%)$ values between 80 and $180 \mathrm{mg} / \mathrm{dL}$ at surgery & $35(73)$ & $25(52)$ & 0.038 \\
\hline Adherence to post-operative glucose control protocol (\%) & $36(75)$ & $19(40)$ & 0.008 \\
\hline Glucose (\%) values between 80 and $180 \mathrm{mg} / \mathrm{dL}$ post-operative & $1094 / 1683(65)$ & $1175 / 1988(59)$ & 0.000 \\
\hline Glucose (\%) values below $60 \mathrm{mg} / \mathrm{dL}$ & $2 / 1683(0.12)$ & $2 / 1988(0.10)$ & 0.894 \\
\hline Surgical site infection $(\%)$ & $8(17)$ & $16(33)$ & 0.065 \\
\hline Urinary tract infection & $4(8)$ & $5(10)$ & \\
\hline Catheter-related infection & $1(2)$ & $4(8)$ & \\
\hline Nosocomial bacteremia & $1(2)$ & $1(2)$ & \\
\hline Nosocomial pneumonia & $1(2)$ & $0(0)$ & \\
\hline Surgical site and other nosocomial infections (\%) & $15(31)$ & $26(54)$ & 0.025 \\
\hline Death $(\%)$ & $2(4)$ & $6(13)$ & 0.145 \\
\hline Hospitalization (days) & $13.67 \pm 12.04$ & $15.02 \pm 15.90$ & 0.390 \\
\hline Hospital readmission $(\%)$ & $0(0)$ & $3(6)$ & 0.242 \\
\hline
\end{tabular}


Table 3. Independent contribution of the program for perioperative glycemic control on the risk of nosocomial infections. Logistic regression analysis.

\begin{tabular}{cccc}
\hline & Odds Ratio & $95 \%$ Confidence Intervals & $P$ \\
\hline NNSI index (for every point) & 3.148 & $1.412-7.016$ & 0.005 \\
Laparoscopic surgery (yes vs no) & 0.814 & $0.245-2.699$ & 0.736 \\
Hospitalization length (per day) & 1.163 & $1.060-1.276$ & 0.001 \\
Group (intervention vs control) & 0.512 & $0.155-1.723$ & 0.014 \\
\hline
\end{tabular}

Addendum Intraoperative subcutaneous insulin protocol for patients treated with oral hypoglycemic agents with appropriate metabolic control defined by hemoglobin ${ }_{\mathrm{Alc}}$ less or equal to $8 \%$ or preoperative blood glucose values below than $200 \mathrm{mg} / \mathrm{dL}$.

\begin{tabular}{cc}
\hline Glucose $(\mathrm{mg} / \mathrm{dL})$ & Insulin dosing (subcutaneous regular short acting insulin) \\
\hline Less than 150 & 0 units \\
$151-200$ & 4 units \\
$201-250$ & 6 units \\
$251-300$ & 8 units \\
Greater than 300 & 10 units \\
\hline
\end{tabular}

Addendum Intraoperative intravenous insulin infusion (rate in $\mathrm{mL}$ per our) used for patients with inappropriate metabolic control defined by hemoglobin $_{\text {Alc }}$ greater than $8 \%$ or preoperative blood glucose values equal or greater than $200 \mathrm{mg} / \mathrm{dL}$.

\begin{tabular}{|c|c|c|c|c|}
\hline & \multicolumn{4}{|c|}{$\begin{array}{c}\text { Continuous intravenous insulin infusion } \\
50 \text { units of regular short acting insulin in } 500 \mathrm{~mL} \text { of } 0.9 \% \text { saline solution }\end{array}$} \\
\hline & $\begin{array}{c}\text { Basal insulin requirement } \\
\text { below } 30 \text { units } \\
\text { per day }\end{array}$ & $\begin{array}{c}\text { Basal insulin requirement } \\
\text { between } 30 \text { and } 50 \text { units } \\
\text { per day }\end{array}$ & $\begin{array}{c}\text { Basal insulin requirement } \\
\text { between } 51 \text { and } 80 \text { units } \\
\text { per day }\end{array}$ & $\begin{array}{l}\text { Basal insulin requirement } \\
\text { greater then } 80 \text { units } \\
\text { per day }\end{array}$ \\
\hline Capillary blood glucose (mg/dL) & Rate (mL/hour) & Rate (mL/hour) & Rate (mL/hour) & Rate (mL/hour) \\
\hline Less than 70 & Stop infusion ${ }^{*}$ & Stop infusion ${ }^{*}$ & Stop infusion ${ }^{*}$ & Stop infusion ${ }^{*}$ \\
\hline $70-90$ & 5 & 7 & 10 & 15 \\
\hline $91-150$ & 10 & 15 & 20 & 30 \\
\hline $151-200$ & 15 & 20 & 25 & 35 \\
\hline $201-250$ & 25 & 30 & 35 & 45 \\
\hline $251-300$ & 30 & 35 & 40 & 50 \\
\hline Greater than 300 & 40 & 45 & 50 & 60 \\
\hline
\end{tabular}

(") Insulin infusion is stopped until next glucose control.

related to strict blood glucose control occurred in a very small proportion of patients. It should be taken into account that compared to patients undergoing clean surgery, as coronary by-pass graft procedures, the population entering our study underwent clean-contaminated or contaminated surgical procedures and had significant underlying conditions defined by the Charlson score.

Most studies have evaluated the safety and efficacy of tight blood glucose control in patients with diabetes undergoing coronary artery bypass graft surgery [17-20]. These protocols included the administration of intravenous insulin and were aimed at obtaining perioperative blood glucose values below $200 \mathrm{mg} / \mathrm{dL}$. The reduction in the rate of surgical site infections obtained was from $90 \%$ [19] to $50 \%$ [18,20]. However, the risk of hypoglycemia was not well described in these studies. A recent study evaluated an insulin infusion protocol aimed at obtaining blood glucose levels below $150 \mathrm{mg} / \mathrm{dL}$ for patients admitted in medical and surgical wards [21-22]. According this protocol, the mean time to achieve the target values was 9 hours but $10 \%$ of a total of 30 patients entering the study suffered from hypoglycemia. Hypoglycemia is a major fear since, as the NICESUGAR study demonstrated, when the target glucose 
control is in the range of 81 to $108 \mathrm{mg} / \mathrm{dL}$ compared to the conventional target values of less than $180 \mathrm{mg} / \mathrm{dL}$, there is an increased risk of mortality and severe hypoglycemia. Using our insulin protocol, the mean preoperative glucose value obtained was $150 \mathrm{mg} / \mathrm{dL}$, and along the postoperative period 65 percent of the capillary glucose readings were between $80-180 \mathrm{mg} / \mathrm{dL}$, with a very low risk of hypoglycemia. These blood glucose values were associated with clinical benefits in terms of a significant reduction in nosocomial infections.

Out study had some limitations; First, intra-operative blood glucose values in the control group were appropriated in a high proportion of patients. Thus, there was small room for improvement. Second, the perioperative insulin protocol was not applied to every patient, therefore the risk of hypoglycaemia could have been underestimated. Specifically, the adherence to intraoperative use of intravenous insulin infusion was lower than expected; however, during hospitalization most patients received insulin as basal-bolus therapy according the proposed algorithm. Third, although for comparison purposes groups were matched by wound class, patients in the control group had lower proportion of laparoscopic surgery compared to the intervention group. It is well known that laparoscopic surgery decreases the risk of surgical site infection and prolongs the time in the operating room [23-25]. In addition, patients undergoing laparoscopic surgery have shorter length of stay in the hospital, which also have impact in the risk to acquire subsequent nosocomial infections. To overcome these potential confounders, we carried out a multivariate analysis taking into account most significant prognosis variables in order to demonstrate the independent contribution of our glucose control protocol for reducing the risk of nosocomial infections. Finally, there are some other prognosis variables not accounted for in our study. These are type of antiseptic preparation, appropriateness of antibiotic prophylaxis, perioperative oxygen inspired fraction, patient body temperature in the operating room, blood transfusion requirements, surgical safety checklists or other best practices that have improved surgical outcomes in recent years. However, in the study period there have not been modifications in the surgical and anaesthetics' protocols in our institution besides improvement in glucose control.

In conclusion, the present before and after study showed that a protocol targeting perioperative glucose values between 80 and $180 \mathrm{mg} / \mathrm{dL}$ with subcutaneous and intravenous insulin was safe and effective to reduce surgical site and other nosocomial infections. Improvements need to be done to implement fully the protocol intra-operatively and post-operatively. Perioperative glucose control should be added to the list of best practices for patients with diabetes undergoing surgery.

\section{ACKNOWLEDGEMENTS}

Contributions: JE conceived and designed the study, collected data, undertook the statistical analysis and drafted the paper; RC assisted in study design, collected data and reviewed the paper; MJC assisted collecting the data and reviewing the paper. EL collected data and reviewed the paper. All authors reviewed and approved the final manuscript.

Funding support: Fundación Mutua Madrileña para la Investigación. Sanofi-Aventis Laboratories. The funds facilitated acquisition of multimedia equipment and supported attendance to local and international meetings.

\section{REFERENCES}

[1] Estrada, C.A., Young, J.A., Nifong, L.W. and Chitwood, W.R. Jr. (2003) Outcomes and preoperative hyperglycemia in patients with or without diabetes mellitus undergoing coronary artery bypass grafting. The Annals of Thoracic Surgery, 75, 1392-1399.

doi:10.1016/S0003-4975(02)04997-4

[2] Pomposelli, J.J., Baxter, J.K. 3rd., Babineau, T.J., Pomfret, E.A., Driscoll, D.F., Forse, R.A. and Bistrian, B.R. (1998) Early postoperative glucose control predicts nosocomial infection rate in diabetic patients. Journal of Parentereral and Enteral Nutrition, 22, 77-81.

doi: $10.1177 / 014860719802200277$

[3] Trick, W.E., Scheckler, W.E., Tokars, J.I., Jones, K.C., Reppen, M.L., Smith, E.M. and Jarvis, W.R. (2000) Modifiable risk factors associated with deep sternal site infection after coronary artery bypass grafting. Journal of Thoracic and Cardiovascular Surgery, 119, 108-114. doi:10.1016/S0022-5223(00)70224-8

[4] Delamaire, M., Maugendre, D., Moreno, M., Le Goff, M.C., Allannic, H. and Genetet, B. (1997) Impaired leucocyte functions in diabetic patients. Diabetic Medicine, 14, 29-34. doi:10.1002/(SICI)1096-9136(199701)14:1<29::AID-DI $\mathrm{A} 300>3.0 . \mathrm{CO} ; 2-\mathrm{V}$

[5] Furnary, A.P., Wu, Y. and Bookin, S.O. (2004) Effect of hyperglycemia and continuous intravenous insulin infusions on outcomes of cardiac surgical procedures: The Portland Diabetic Project. Endocrine Practice, 10, 21-33.

[6] Van den Berghe, G., Wouters, P., Weekers, F., Verwaest, C., Bruyninckx, F., Schetz, M., Vlasselaers, D., Ferdinande, P., Lauwers, P. and Bouillon, R. (2001) Intensive insulin therapy in the critically ill patients. New England Journal of Medicine, 345, 1359-1367. doi:10.1056/NEJMoa011300

[7] Mangram, A.J., Horan, T.C., Pearson, M.L., Silver, L.C. and Jarvis, W.R. (1999) Guideline for prevention of surgical site infection, 1999. Hospital infection control practices advisory committee. Infection Control and Hospital Epidemiology, 20, 250-278. doi:10.1086/501620

[8] Moghissi, E.S., Korytkowski, M.T., DiNardo, M., Einhorn, D., Hellman, R., Hirsch, I.B., Inzucchi, S.E., Ismail-Beigi, F., Kirkman, M.S. and Umpierrez, G.E. (2009) American Association of Clinical Endocrinologists and American Diabetes Association Consensus Statement on inpatient glycemic control. Diabetes Care, 32, 1119-1131. doi:10.2337/dc09-9029 
[9] Ena, J., Casan, R., Lozano, T., Leach, A., Algado, J.T. and Navarro-Diaz, F.J. (2009) Long-term improvements in insulin prescribing habits and glycemic control in medical inpatients associated with the introduction of a standardized educational approach. Diabetes Research and Clinical Practice, 85, 159-165. doi:10.1016/j.diabres.2009.05.011

[10] D'Hoore, W., Sicotte, C. and Tilquin, C. (1993) Risk adjustment in outcome assessment: The Charlson comorbidity index. Methods of Information in Medicine, 32, 382-387.

[11] Knaus, W.A., Draper, E.A., Wagner, D.P. and Zimmerman, J.E. (1985) APACHE II: A severity of disease classification system. Critical Care Medicine, 13, 818-829. doi:10.1097/00003246-198510000-00009

[12] Owens, W.D., Felts, J.A. and Spitznagel, E.L. Jr. (1978) ASA physical status classifications: A study of consistency of ratings. Anesthesiology, 49, 239-243. doi:10.1097/00000542-197810000-00003

[13] Haley, R.W., Culver, D.H., Morgan, W.M., White, J.W., Emori, T.G. and Hooton, T.M. (1985) Identifying patients at high risk of surgical wound infection. A simple multivariate index of patient susceptibility and wound contamination. American Journal of Epidemiology, 121, 206215.

[14] Emori, T.G., Culver, D.H., Horan, T.C., Jarvis, W.R., White, J.W., Olson, D.R., Banerjee, S., Edwards, J.R., Martone, W.J., Gaynes, R.P., et al. (1991) National nosocomial infections surveillance system (NNIS): Description of surveillance methods. American Journal of Infection Control, 19, 19-35. doi:10.1016/0196-6553(91)90157-8

[15] Horan, T.C., Gaynes, R.P., Martone, W.J., Jarvis, W.R. and Emori, T.G. (1992) CDC definitions of nosocomial surgical site infections, 1992: A modification of CDC definitions of surgical wound infections. Infection Control and Hospital Epidemiology, 13, 606-608. doi:10.1086/646436

[16] McKibben, L., Horan, T., Tokars, J.I., Fowler, G., Cardo, D.M., Pearson, M.L., Brennan, P.J. (2005) Guidance on public reporting of healthcare-associated infections: Recommendations of the healthcare infection control practices advisory committee. American Journal of Infection Control, 33, 217-226. doi:10.1016/j.ajic.2005.04.001

[17] Latham, R., Lancaster, A.D., Covington, J.F., Pirolo, J.S. and Thomas, C.S. (2001) The association of diabetes and glucose control with surgical-site infections among cardiothoracic surgery patients. Infection Control and Hos- pital Epidemiology, 22, 607-612. doi:10.1086/501830

[18] Furnary, A.P., Zerr, K.J., Grunkemeier, G.L. and Starr, A. (1999) Continuous intravenous insulin infusion reduces the incidence of deep sternal wound infection in diabetic patients after cardiac surgical procedures. Annals of Thoracic Surgery, 67, 352-360. doi:10.1016/S0003-4975(99)00014-4

[19] Lazar, H.L., Chipkin, S.R., Fitzgerald, C.A., Bao, Y., Cabral, H. and Apstein, C.S. (2004) Tight glycemic control in diabetic coronary artery by pass graft patients improves preoperative outcomes and decreases recurrent ischemic events. Circulation, 109, 1497-1502. doi:10.1161/01.CIR.0000121747.71054.79

[20] Barcellos, C.S., Wender, O.C.B. and Azambuja, P.C. (2007) Clinical and haemodynamic outcome following coronary artery by pass surgery in diabetic patients using glucose-insulin-potassium (GIK) solution: A randomized clinical trial. Revista Brasileira de Cirurgia Cardiovascular, 22, 275-284. doi:10.1590/S0102-76382007000300002

[21] Vinik, R., Jones, R.E., Pendleton, R.C. and Ku, S.Y. (2009) Safety and efficacy of an infusion protocol designed for the non-intensive care setting. Endocrine Practice, 15, 682-688. doi:10.4158/EP09055.ORR

[22] NICE-SUGAR Study Investigators: Finfer, S., Chittock, D.R., Su, S.Y., Blair, D., Foster, D., Dhingra, V., Bellomo, R., Cook, D., Dodek, P., Henderson, W.R., Hébert, P.C., Heritier, S., Heyland, D.K., McArthur, C., McDonald, E., Mitchell, I., Myburgh, J.A., Norton, R., Potter, J., Robinson, B.G. and Ronco, J.J. (2009) Intensive versus conventional glucose control in critically ill patients. New England Journal of Medicine, 360, 1283-1297. doi:10.1056/NEJMoa0810625

[23] Nakamura, T., Onozato, W., Mitomi, H., Sato, T., Hatate, K., Naioto, M., Ihara, A. and Watanabe, M. (2009) Analysis of the risk factors for wound infection after surgical treatment of colorectal cancer: A matched case control study. Hepatogastroenterology, 56, 1316-1320.

[24] Romy, S., Eisenring, M.C., Bettschart, V., Petignat, C., Francioli, P. and Troillet, N. (2008) Laparoscope use and surgical site infections in digestive surgery. Annals of Surgery, 247, 627-632. doi:10.1097/SLA.0b013e3181638609

[25] Biscione, F.M., Couto, R.C., Pedrosa, T.M. and Neto, M.C. (2007) Comparison of the risk of surgical site infection after laparoscopic cholecystectomy and open cholecystectomy. Infection Control and Hospital Epidemiology, 28, 1103-1106. doi:10.1086/519931

\section{ADDENDUM}

ADA: American Diabetes Association;

APACHE-II: Acute Physiologic and Chronic Health Evaluation;

ASA: American Anesthetists Association;

CDC: Centers for Disease Control;

CI: Confidence intervals;

NNIS: National Nosocomial Infections Surveillance;

SD: Standard Deviation. 